\title{
Peripartum cardiomyopathy: an obstetric review
}

\author{
Priyanka Sharma $^{1 *}$, Binay Kumar ${ }^{2}$
}

\begin{abstract}
${ }^{1}$ Department of Obstetrics and Gynaecology, Lady Hardinge Medical College, New Delhi, India
${ }^{2}$ Department of Cardiology, All India Institute of Medical Sciences, New Delhi, India
\end{abstract}

Received: 13 December 2016

Accepted: 07 January 2017

\section{*Correspondence:}

Dr. Priyanka Sharma,

E-mail: priyanka_labelle@yahoo.co.in

Copyright: (C) the author(s), publisher and licensee Medip Academy. This is an open-access article distributed under the terms of the Creative Commons Attribution Non-Commercial License, which permits unrestricted non-commercial use, distribution, and reproduction in any medium, provided the original work is properly cited.

\begin{abstract}
Peripartum cardiomyopathy (PPCM) is a rare and potentially fatal form of systolic heart failure which presents in later months of pregnancy and post-partum. Incidence varies over geography and ethnicity. It is highest in the African tribes of Hausa and Fulani. The incidence in the United States ranges from 1 in 1500-7500 births. Risk factors include advanced maternal age, multiparity, preeclampsia, multifetal gestation and African descent. Various etiologies such as viral myocarditis, abnormal immune and hemodynamic response to pregnancy, inflammatory mediation and genetic susceptibility have been proposed. Of late, the role of abnormal prolactin metabolism and resulting myocardial toxicity have been explored and bromocriptine has shown promise as a potential treatment option. Medical management is similar to other causes of systolic heart failure, except that ACE inhibitors and angiotensin receptor blockers are avoided in pregnancy. Complications include cardiac arrhythmias, thromboembolism and refractory heart failure can occur. Maternal deaths are not uncommon.
\end{abstract}

Keywords: BNP, PPCM, Prolactin

\section{INTRODUCTION}

Peripartum cardiomyopathy (PPCM) is a rare and potentially life-threatening form of heart failure affecting women late in pregnancy or in the first months after delivery. PPCM is difficult to diagnose and its onset and progression are variable amongst individuals. The pathophysiology remains poorly understood; hence treatment options are limited and, some, possibly harmful to the foetus.

\section{HISTORICAL PERSPECTIVE AND DEFINITION}

Historically, the association between heart failure and pregnancy has been described since the $19^{\text {th }}$ century. ${ }^{1,2}$ However, PPCM was first recognized as a distinctive form of cardiomyopathy in 1937, when Gouley et al noticed features of severe heart failure with an atypical and distinct dilated cardiomyopathy in later months of pregnancy in 7 pregnant females, which persisted after delivery. ${ }^{3}$

The Heart Failure Association of the European Society of Cardiology Working Group on PPCM has defined it as an idiopathic cardiomyopathy presenting with heart failure secondary to left ventricular (LV) systolic dysfunction towards the end of pregnancy or in the months following delivery, where no other cause of heart failure is found. ${ }^{4}$ It is a diagnosis of exclusion. The LV may not be dilated but the ejection fraction is nearly always reduced below $45 \%$. The echocardiographic criteria proposed for LV dysfunction are as follows 5

- Ejection fraction $<45 \%$ or fractional shortening $<30 \%$

- End-diastolic dimension $>2.7 \mathrm{~cm} / \mathrm{m}^{2}$ 


\section{EPIDEMIOLOGY}

Population based data on PPCM is scant. Incidence fluctuates widely between ethnicities and over geography. The highest reported incidence is in the Hausa and Fulani tribes of Nigeria where the incidence is as high as 1 in 100 deliveries. ${ }^{6}$ This high incidence seems related to the unique puerperal practices of these tribes which include postpartum excess consumption of dried lake salt, warm water baths and lying on heated mud beds during the cold dry climate leading to a propensity towards volume overload. In South Africa, the incidence is 1 in 1000 deliveries. $^{7}$

In the United States, the incidence reportedly ranges from 1 in 1,149 to 1 in 4,350 live births to 1 in 7500 in $2007 .^{8-}$

${ }^{11}$ In the United States, the lowest observed incidence is reported in Hispanics and the highest in AfricanAmericans. ${ }^{12}$ The Peripartum Cardiomyopathy Project in Haiti estimates the incidence of PPCM to be as high as 1 in 299 live births. ${ }^{13}$ A study conducted in a tertiary hospital in South India reported an incidence of 1case per 1374 deliveries, with advanced maternal age and multiparity being the foremost risk factors. ${ }^{14}$

\section{RISK FACTORS AND ETIOPATHOGENESIS}

Risk factors include increased maternal age, multiparity, preeclampsia, multifetal gestation, African descent, use of tocolytics, poverty, tobacco use, malnutrition and anemia during index pregnancy. ${ }^{10,12,15-18}$

Although initially considered to be a variant of dilated cardiomyopathy, it is now accepted that PPCM is a distinct entity rather than a clinically silent underlying cardiomyopathy exacerbated by the hemodynamic changes during pregnancy. The two-share common clinical presentation and hemodynamic features, yet several distinctive features set them apart. PPCM is diagnosed in a younger set of patients (in the peripartum period) as opposed to idiopathic dilated cardiomyopathy which is seen in older patients. It characteristically presents in late pregnancy and puerperium and does not coincide with the periods of maximum hemodynamic load observed in pregnancy. Recovery is often complete as opposed to idiopathic dilated cardiomyopathy where recovery is rare. The histological picture is also different in the two diseases.

The etiology of PPCM is still unknown, and many potential causes have been proposed but not conclusively proven. These include viral myocarditis, abnormal immune response to pregnancy, abnormal response to increased hemodynamic burden of pregnancy, hormonal abnormalities, malnutrition, inflammation and apoptosis. New experimental animal models indicate the role of a novel molecular pathogenetic mechanism involving a cardiomyocyte-specific deletion of the transcription factor signal transducer and activator of transcription (STAT3) protein. ${ }^{19}$

\section{Role of prolactin}

Experimental evidence has implicated abnormal prolactin metabolism as fundamental in the pathogenesis of PPCM. The proposed mechanism is unbalanced oxidative stress leading to the cleavage of full length $23 \mathrm{kDa}$ prolactin to an angiostatic and proapoptotic $16 \mathrm{kDa}$ form. The fulllength $23-\mathrm{kDa}$ prolactin has no adverse effects on the heart. In contrast, high expression of $16-\mathrm{kDa}$ fragment destroys the cardiac microvasculature, reduces in vivo cardiac function and promotes ventricular dilatation. It also inhibits VEGF-induced proliferation and migration of endothelial cells, induces apoptosis, dissociation of capillary structures, impairs NO-mediated vasodilatation, and cardiomyocyte function. ${ }^{19}$ Most recently, experimental work has demonstrated the development of PPCM in female mice with a cardiomyocyte-specific deletion of the STAT3 protein. This increases oxidative stress and results in increased expression and proteolytic activity of cardiac cathepsin D. The resulting cleavage of prolactin into the 16-kDa form leads to detrimental effect on the myocardial microvasculature resulting in myocardial hypoxemia and apoptosis, and the development of PPCM. Blockade of prolactin with bromocriptine has been shown to prevent PPCM in experimental models. ${ }^{19}$

\section{Angiogenic imbalance}

Data from studies in mice and humans suggests that PPCM may be caused by systemic angiogenic imbalance. ${ }^{18,20,21}$ Mice that lack cardiac peroxisome proliferator-activated receptor gamma coactivator 1-alpha (PGC-1 $\alpha$ ), a regulator of pro-angiogenic factors such as VEGF, develop severe PPCM. This may also explain why preeclampsia and multiple gestations are risk factors for PPCM. During late gestation, the human placenta secretes VEGF inhibitors such as soluble fms-like tyrosine kinase (sFLt1), which also damage the vasculature, with higher levels seen with multiple gestation or preeclampsia. ${ }^{20}$ Among women with preeclampsia, subclinical cardiac dysfunction (as detected by the myocardial performance index) correlates with sFlt1 levels. ${ }^{20}$

\section{Viral myocarditis}

Several investigators have suggested viral infection as cause of myocarditis in PPCM. One study evaluated 11 African women presenting clinically with PPCM. Endomyocardial biopsies in five patients were consistent with a "healing" myocarditis. ${ }^{22}$ In two other series, myocarditis was present in 4 of $14(28 \%)$ patients with PPCM and in only 5 of 55 patients $(9 \%)$ in a control group with an idiopathic cardiomyopathy. ${ }^{23}$ The study of endomyocardial biopsies in PPCM patients found a high prevalence of viral genomes (parvovirus B19, cytomegalovirus, herpes virus 6 and Epstein-Barr virus) as well as inflammatory changes consistent with myocarditis. $^{24}$ 
In contrast, a retrospective review of endomyocardial biopsy specimens from 34 patients of PPCM found a lower incidence of myocarditis $(9 \%)$ than that reported in other studies. ${ }^{25}$ It is possible that post viral immune response directed inappropriately against native cardiac tissue proteins, in the presence of the characteristic hemodynamic changes during pregnancy, leads to LV systolic dysfunction. However, in view of conflicting data, the role of viral infections in PPCM is far from conclusive.

\section{Inflammatory cytokines}

Inflammatory cytokines may play a role in the pathogenesis and progression of cardiomyopathy and heart failure. The cytokines that are elevated in PPCM compared to controls include tumour necrosis factor (TNF)-alpha and interleukin-6. ${ }^{26,27}$ In addition, Fas/Apo1 , an apoptosis signalling receptor, and CRP are associated with more severe disease. ${ }^{27}$

\section{Abnormal autoimmune response}

An abnormal immune response may be produced after previous exposure immunization from prior pregnancy, or previous exposure to paternal major histocompatibility antigens. A local tissue inflammatory response is induced, followed by release of cytokines which causes a nonspecific bystander myotoxicity and myocarditis. ${ }^{28}$

Circulating auto-antibodies to selected cardiac tissue proteins were reported by several studies in more than $50 \%$ of PPCM patients. Auto-antibodies are associated with increased levels of cytokines (TNF-alpha, interleukin-6, soluble Fas receptors), and are correlated with dilatation of LV and systolic dysfunction. ${ }^{26,27,29}$

It was reported that in all patients with PPCM, irrespective of geographic location, auto-antibodies of IgG class are non-selectively increased against cardiac myosin. ${ }^{30}$ Studies have reported the phenomenon called chimerism, where fetal cells of hematopoietic origin reside in maternal serum, but remain undetected because of the weak immunogenicity of paternal haploytpe or maternal altered immunity. ${ }^{31}$ An immune response may be triggered against the fetal cells lodged in the maternal myometrium with postpartum immune recovery. ${ }^{28}$

\section{Genetic Susceptibility}

PPCM has been classified as a non-genetic form of idiopathic dilated cardiomyopathy. However, a number of studies have reported familial clustering. A European study found PPCM in 6\% of 90 families with idiopathic dilated cardiomyopathy. ${ }^{32}$ Screening of first-degree relatives of 3 patients with PPCM with persistent LV dysfunction revealed undiagnosed dilated cardiomyopathy (DCM) in all 3 families. Furthermore, genetic analyses showed a mutation in the gene encoding cardiac troponin $\mathrm{C}$ in 1 DCM family with members with
PPCM ${ }^{33}$ These findings suggest that, in a proportion of patients, PPCM is due to genetic causes or represents cases of familial DCM that was unmasked or first recognized in pregnancy.

\section{CLINICAL PRESENTATION}

The diagnosis of PPCM presents a challenge as its presentation may mimic other causes of systolic heart failure or even, exaggerated signs and symptoms of late pregnancy and early puerperium. The most common symptoms are dyspnea (typically NYHA Class III/IV), fatigue $(90 \%)$, tachycardia $(62 \%)$, and peripheral edema $(60 \%)$. Persistent nocturnal dry cough, orthopnea and paroxysmal nocturnal dyspnea are frequently reported. ${ }^{34}$ Other non-specific symptoms include dizziness, chest pain, abdominal discomfort and palpitations. Rarely, acute cyanosis, thromboembolic episodes and liver failure have also been reported. ${ }^{35,36}$ Systemic and pulmonary embolic episodes are more frequent with PPCM than other cardiomyopathies. ${ }^{37-39}$ Sudden cardiac arrest may occur. ${ }^{40}$

Regarding the physical signs in PPCM, sinus tachycardia is almost universal. Supraventricular tachycardia and complex ventricular arrhythmias are common. ${ }^{40,41} \mathrm{~A}$ high incidence of the third heart sound and displaced apical impulse is reported. New murmurs consistent with mitral and tricuspid regurgitation are present in almost $50 \%$ of PPCM patients. ${ }^{42}$ In later stages, signs of pulmonary hypertension, including a loud or split S2 and crepitations, are common. Elevated jugular venous pressure and hepatomegaly with edema suggest right heart failure.

Blood pressure may be normal or increased. In later stages, postural hypotension can occur.4 $78 \%$ of PPCM cases develop heart failure symptoms in the first 4 months after delivery, and only $9 \%$ of patients present in the last month of pregnancy. ${ }^{43}$

In conclusion, there are no specific criteria for differentiating symptoms of early heart failure from normal late pregnancy. So, it is imperative to maintain a high index of suspicion with attention to timing of symptoms, and perform thorough investigation to rule out other causes of heart failure.

\section{INVESTIGATIONS}

\section{Electrocardiogram}

ECG findings in patients with PPCM are nonspecific and include sinus tachycardia (or rarely, atrial fibrillation), nonspecific ST and T wave abnormalities, and voltage abnormalities (low voltage or criteria for $\mathrm{LV}$ hypertrophy). Q waves are occasionally present in the anterior precordium. PR and QRS intervals may be prolonged. ${ }^{44}$ An ECG is helpful in identifying differential 
diagnosis such as myocardial infarction and pulmonary embolism.

\section{Brain natriuretic peptide (BNP)}

Women presenting with PPCM typically have elevated BNP and NT-proBNP levels that are higher than seen in healthy women during pregnancy or postpartum. ${ }^{45}$

\section{Chest radiograph}

The chest radiograph typically shows enlargement of the cardiac silhouette with evidence of pulmonary venous congestion and/or interstitial edema, and, on occasion, pleural effusions. However, a chest radiograph is not essential to make a diagnosis of heart failure or PPCM, and exposes the patient to ionizing radiation. If deemed necessary, it can be considered in pregnant women with fetal shielding.

\section{Echocardiography}

The echocardiogram generally reveals a global reduction in LV systolic function with LVEF nearly always $<45 \%$. The left ventricle is frequently but not always dilated.4 Other possible echocardiographic findings include left atrial enlargement, LV or left atrial thrombus, dilated right ventricle, right ventricular hypokinesis, mitral and tricuspid regurgitation, and rarely small pericardial effusion.44 It is strongly recommended to monitor the evolution under treatment before patient's discharge, at 6 weeks, 6 months, and annually. ${ }^{4}$

\section{Cardiac magnetic resonance imaging}

Cardiac magnetic resonance imaging (CMR) is not generally required to make the diagnosis of PPCM but it can be helpful to assess LV systolic function and LV volumes, particularly if echocardiography is technically suboptimal. Case reports and small series have noted variable presence of late gadolinium enhancement in patients with PPCM. However, the prognostic value of CMR in PPCM has not been established.

\section{Cardiac catheterization}

Cardiac catheterisation is generally not recommended unless deemed necessary to exclude coronary artery disease as a potential cause of myocarditis.

\section{Endomyocardial biopsy}

Endomyocardial biopsy is generally not required in patients with suspected PPCM but may be performed if deemed necessary to exclude other potential causes of cardiomyopathy with diagnostic features on biopsy. There are no pathognomonic findings in PPCM. Histologic findings in PPCM can include myocarditis, myofiber hypertrophy and/or degeneration, fibrosis and interstitial edema. ${ }^{22,46}$

\section{Other tests}

Viral and bacterial cultures and titres are generally not indicated. CRP may be elevated. The results of these tests are nonspecific and thus without proven value in patients with myocarditis.

\section{MANAGEMENT}

\section{Medical therapy}

The management is similar to that of systolic heart failure of other etiologies. In acute heart failure, airway, breathing and circulation are maintained. Intravenous loop diuretics, mostly furosemide, and vasodilators such as nitrates and hydralazine are used for preload and afterload reduction. Caution must, however, be exercised to avoid severe hypotension or reduction in uteroplacental flow. ACE inhibitors and Angiotensin receptor blockers are contraindicated in pregnancy but may be used post partum. Thiazide diuretics may cause neonatal hyponatremia and bleeding diathesis. Beta blockade is avoided in acute decompensated heart failure but has an established role in chronic decompensation. Beta- 1 selective blockers are preferred to avoid untoward uterine effects. Metoprolol is the agent of choice.

Inotropic support is provided in cardiogenic shock and pulmonary edema that are refractory to initial management with diuretics and vasodilators. Vasopressors may be considered in critically ill patients after weighing benefit against the risks of increased systemic vascular resistance which can further impair cardiac output and uteroplacental blood flow.

Digoxin may be used as a second line therapy in NYHA Class III and IV symptoms in selected patients. It is safe in pregnancy. Though it is minimally secreted in breast milk, there are no reported adverse effects in new borns.

Pregnancy and puerperium are hypercoagulable states. Anticoagulation is advisable when LVEF falls below $35 \%$, or in case of atrial fibrillation or mural thrombi during pregnancy and at least 2 months post-partum. Unfractionated heparin is preferred as it does not cross the placenta and is non-teratogenic. It has a shorter duration of action and its effect is reversible which is beneficial in case of unexpected onset of labour. Both warfarin and heparin are safe in puerperium and breastfeeding.

Sudden death and ventricular arrhythmias are common in PPCM. Beta blockers may be used to treat supraventricular tachyarrythmias. Other antiarrythmics are not entirely safe in pregnancy and use has to be weighed against risk. There are no clear indications for implantable cardioverter defibrillator (ICD) and cardiac resynchronisation therapy in PPCM. Upto 40\% PPCM patients may recover completely. T herefore, early ICD placement should be avoided for 3-6 months after 
presentation. It might be reasonable to consider ICDs in patients with EF $<30 \%$, who are at high risk of complications including sudden death, as a bridge to recovery or in those who fail to recover on optimal medical therapy. ${ }^{47}$ Intra-aortic balloon pumps, LV and biventricular assist devices, and extracorporeal membrane oxygenation should be considered in these cases. ${ }^{47}$

\section{Novel Targeted Therapies}

\section{Bromocriptine}

This treatment strategy is based upon experimental observation of prevention of PPCM in mice via prolactin blockade with bromocriptine. ${ }^{19}$

A prospective, single-centre, open-label, proof-ofconcept pilot study of women with newly diagnosed PPCM randomised patients into those receiving standard care $(n=10)$ and those receiving standard care plus bromocriptine $(n=10)$ for 8 weeks. PPCM-Br patients displayed greater recovery of LVEF compared with PPCM-Std patients at 6 months. ${ }^{48}$

This drug appears promising but there is insufficient evidence to establish the safety and efficacy of bromocriptine treatment for PPCM. Larger trials are needed.

\section{Immunosuppressive agents}

Empiric immunosuppression is not recommended. These drugs often have significant side effects, and studies in other forms of myocarditis have not shown clear benefit from immunosuppressive therapy.

\section{Intravenous immune globulin}

Intravenous immune globulin (IVIG) has been tried in patients with myocarditis or recent-onset dilated cardiomyopathy with no clear evidence of clinical benefit. A retrospective study of six women with PPCM treated with IVIG and 11 controls found a greater increase in LVEF at six months in patients treated with IVIG compared to controls (26 v/s 13\%). ${ }^{49}$ However, the efficacy of this approach has not been confirmed.

\section{DELIVERY}

In women with PPCM with advanced heart failure, prompt delivery for maternal cardiovascular indications is suggested. Planned caesarean delivery is preferred for women with advanced heart failure requiring inotropic therapy or mechanical circulatory support. The 2010 European Society of Cardiology working group statement has advised that early delivery is not required if the maternal and fetal conditions are stable. ${ }^{4}$ However, patient-specific issues, including gestational age, cervical status, fetal status, and the potential cardiovascular impact of continuing pregnancy should be considered in timing delivery. As for women with other types of cardiac conditions, caesarean delivery in patients with stable cardiovascular status is generally reserved for obstetrical indications. Epidural analgesia is preferred during labour, as it stabilizes cardiac output through a sympathectomy-induced afterload reduction.4 Continuous spinal anesthesia, with epidural analgesia are recommended for caesarean section, as the hemodynamic stability may be more easily maintained. ${ }^{50}$

\section{BREASTFEEDING}

Some experts, including the 2010 European Society of Cardiology working group, suggest that breastfeeding be avoided because of the potential effects of prolactin sub fragments. ${ }^{4}$ Overall, given the benefits of breastfeeding, women who are clinically stable should not be discouraged from breastfeeding if it is compatible with other medication.

\section{PROGNOSIS}

The prognosis of PPCM must take into account maternal, obstetric, and neonatal outcomes, and the effect of subsequent pregnancy.

\section{Maternal outcome}

Studies have reported recovery of LV function at 6 months in $45 \%$ to $78 \%$ of patients, with a mean of $54 \% .^{51,52}$ with improvement occurring mostly within the first 6 months.Mortality rates have varied between $0 \%$ and $19 \%$, while rates of cardiac transplantation have ranged from $6 \%$ to $11 \% .^{8-11,51}$

The predictors of maternal mortality are poor NYHA status, LVEF $<30 \%$, higher maternal age, black race and multiparity. ${ }^{52}$ Predictors of persistent LV dysfunction at follow up are LVEF $<30 \%$, fractional shortening $<20 \%$ and LV end-diastolic dimension $>6 \mathrm{~cm}$, elevated cardiac troponin $\mathrm{T}$ and black race. ${ }^{52}$

\section{Subsequent pregnancy and risk of relapse}

Women with PPCM or history of PPCM should receive counselling regarding the risk of recurrence with subsequent pregnancies. Individual planning might be done after an echocardiogram is performed:

- If LV ejection fraction is $<25 \%$ at diagnosis or incompletely recovered, the advice should be against further pregnancy. ${ }^{4}$

- If LV function is normal, stress-echocardiography should be performed:

a) Women with an abnormal LV inotropic response to dobutamine have a moderate risk of relapse and pregnancy is not recommended. ${ }^{4}$

b) Women with complete recovery on both echocardiography and dobutamine stress test can be 
informed about the low rate of complications. In this group, despite a $35 \%$ rate of risk of recurrence, pregnancy can be completed in almost all cases. ${ }^{54}$

In the postpartum period, contraceptive counselling is essential to educate the patients about existing alternatives. Pregnancy should be avoided till LV function has recovered. Combined estrogen- progesterone contraceptives are contraindicated, as estrogens increase the thromboembolic risk. Progesterone-only contraception is permitted. Barrier methods are not favoured due to high failure rates. IUCDs are the most efficient and safe methods of contraception. Sterilization methods, including vasectomy, tubal ligation, and insertion of intratubal stents may be considered.

\section{CONCLUSION}

Peripartum cardiomyopathy is a form of systolic heart failure of relatively obscure etiology. It presents in later months of pregnancy and post partum. Incidence varies over geography and ethnicity. It is highest in the African tribes of Hausa and Fulani. The incidence in the United States ranges from 1 in 1500-4000 births. African ethnicity, multifetal gestation, maternal age and preeclampsia are strong risk factors.

Various etiologies such as viral myocarditis, abnormal immune and hemodynamic response to pregnancy, inflammatory mediation and genetic susceptibility have been proposed. Of late, the role of abnormal prolactin metabolism, and resulting myocardial toxicity have been explored and bromocriptine has shown promise in treatment.

Medical management is similar to other causes of systolic heart failure, except that ACE inhibitors and angiotensin receptor blockers are avoided in pregnancy. Complications include cardiac arrhythmias, thromboembolism and refractory heart failure can occur. Maternal mortality ranges from 0-19\%.

Funding: No funding sources Conflict of interest: None declared

Ethical approval: Not required

\section{REFERENCES}

1. Ritchie C. Clinical contribution to the pathology, diagnosis and treatment of certain chronic diseases in the heart. Edinburgh Med Surg. 1849;2:333-5.

2. Porak C. De l'influence reciproque de la grossesse et des maladies du Couer, thesis, Paris. 1880.

3. Gouley BA, McMillan TM, Bellet S. Idiopathic myocardial degeneration associated with pregnancy and especially the puerperium. Am J Med Sci. 1937;194:185-99.

4. Sliwa K, Hilfiker-Kleiner D, Petrie MC, Mebazaa A, Pieske B, Buchmann E, et al. Current state of knowledge on aetiology, diagnosis, management, and therapy of peripartum cardiomyopathy: a position statement from the Heart Failure Association of the European Society of Cardiology Working Group on peripartum cardiomyopathy. Eur J Heart Fail. 2010;12(8):767-8.

5. Hibbard JU, Lindheimer M, Lang RM. A modified definition for peripartum cardiomyopathy and prognosis based on echocardiography. Obstet Gynecol. 1999;94(2):311-6.

6. Isezuo SA, Abubakar SA. Epidemiologic profile of peripartum cardiomyopathy in a tertiary care hospital. Ethn Dis. 2007;17(2):228-33.

7. Gentry MB, Dias JK, Luis A, Patel R, Thornton, Reed GL. African-American women have a higher risk for developing peripartum cardiomyopathy. J Am Coll Cardiol. 2010;55(7):654-9.

8. Witlin AG, Mabie WC, Sibai BM. Peripartum cardiomyopathy: an omnious diagnosis. Am J Obstet Gynecol. 1997;176(1 Pt 1):182-8.

9. Chapa JB, Heiberger HB, Weinert L, DeCara J, Lang R, Hibbard JU. Prognostic value of echocardiography in peripartum cardiomyopathy. Obstet Gynecol. 2005;105(6):1303-8.

10. Mielniczuk LM, Williams L, Davis DR, Tang AS, Lemery R, Green MS, et al. Frequency of peripartum cardiomyopathy. Am J Cardiol. 2006;97(12):1765-8.

11. Brar SS, Khan SS, Sandhu GK, Jorgensen MB, Parikh N, Hsu JW, et al. Incidence, mortality, and racial differences in peripartum cardiomyopathy. Am J Cardiol. 2007;100(2):302-4.

12. Kao DP, Hsich E, Lindenfeld J. Characteristics, adverse events, and racial differences among delivering mothers with peripartum cardiomyopathy. JACC Heart Fail. 2013;1(5):409-16.

13. Fett JD, Christie LG, Carraway RD, Murphy JG. Five-year prospective study of the incidence and prognosis of peripartum cardiomyopathy at a single institution. Mayo Clin Proc. 2005;80(12):1602-6.

14. Pandit V, Shetty S, Kumar A, Sagir A. Incidence and outcome of peripartum cardiomyopathy from a tertiary hospital in South India. Trop Doct. 2009;39(3):168-9.

15. Gunderson EP, Croen LA, Chiang V, Yoshida CK, Walton D, Go AS. Epidemiology of peripartum cardiomyopathy: incidence, predictors, and outcomes. Obstet Gynecol. 2011;118(3):583-91.

16. Elkayam U. Clinical characteristics of peripartum cardiomyopathy in the United States: diagnosis, prognosis, and management. J Am Coll Cardiol. 2011;58(7):659-70.

17. Lampert MB, Hibbard J, Weinert L, Briller J, Lindheimer M, Lang RM. Peripartum heart failure associated with prolonged tocolytic therapy.Am J Obstet Gynecol. 1993;168(2):493-5.

18. Bello N, Rendon IS, Arany Z. The relationship between pre-eclampsia and peripartum cardiomyopathy: a systematic review and metaanalysis. J Am Coll Cardiol. 2013;62(18):1715-23.

19. Hilfiker-Kleiner D, Kaminski K, Podewski E, Bonda T, Schaefer A, Sliwa K, et al. A cathepsin D-cleaved 
$16 \mathrm{kDa}$ form of prolactin mediates postpartum cardiomyopathy. Cell 2007;128(3):589-600.

20. Patten IS, Rana S, Shahul S, Rowe GC, Jang C, Liu $\mathrm{L}$, et al. Cardiac angiogenic imbalance leads to peripartum cardiomyopathy. Nature. 2012;485(7398):333-8.

21. Sliwa K, Mebazaa A. Possible joint pathways of early pre-eclampsia and congenital heart defects via angiogenic imbalance and potential evidence for cardio-placental syndrome. Eur Heart J. 2014;35(11):680-2.

22. Sanderson JE, Olsen EG, Gate J D. Peripartum heart disease: an endomyocardial biopsy study. Br Heart J. 1986;56:285-91.

23. O'Connell JB, Costanzo-Nordin MR, Subramanian R, Robinson JA, Wallis DE, Scanlon PJ, et al. Peripartum cardiomyopathy: clinical, hemodynamic, histologic and prognostic characteristics. J Am Coll Cardiol. 1986;8(1):52-6.

24. Bultmann BD, Klingel, K, Nabauer M, Wallwiener D, Kandolf R. High prevalence of viral genomes and inflammation in peripartum cardiomyopathy. Am J Obstet Gynecol. 2005;193(2):363-5.

25. Rizeq MN, Rickenbacher PR, Fowler MB, Billingham ME. Incidence of myocarditis in peripartum cardiomyopathy. Am J Cardiol. 1994;74(5):474-7.

26. Sliwa K, Skudicky D, Bergemann A, Candy G, Puren A, Sareli P. Peripartum cardiomyopathy: analysis of clinical outcome, left ventricular function, plasma levels of cytokines and Fas/APO-1. J Am Coll Cardiol. 2000;35(3):701-5.

27. Sliwa K, Förster O, Libhaber E, Fett JD, Sundstrom JB, Hilfiker-Kleiner D, et al. Peripartum cardiomyopathy: inflammatory markers as predictors of outcome in 100 prospectively studied patients. Eur Heart J. 2006;27(4):441-6.

28. Pearson GD, Veille JC, Rahimtoola S, Hsia J, Oakley CM , Hosenpud JD, et al. Peripartum cardiomyopathy. National Heart Lung and Blood Institute and Office of Rare Diseases (National Institutes of Health) Workshop recommendations and review. JAMA. 2000;283(9)-1183-4.

29. Sliwa K, Fett J, Elkayam U. Peripartum cardiomyopathy. Lancet. 2006;368(9536):687-93.

30. Warraich RS, Sliwa K, Damasceno A, Carraway R, Sundrom B, Arif G, et al. Impact of pregnancyrelated heart failure on humoral immunity: clinical relevance of G3-subclass immunoglobulins in peripartum cardiomyopathy. Am Heart J. 2005;150(2):263-9.

31. Ramaraj R, Sorrell VL. Peripartum cardiomyopathy: causes, diagnosis, and treatment. Clev Clin J Med 2009; 76(5):289-96.

32. Van Spaendonck-Zwarts KY, van Tintelen JP, van Veldhuisen DJ, van der Werf R, Jongbloed JD, Paulus WJ, et al. Peripartum cardiomyopathy as a part of familial dilated cardiomyopathy. Circulation 2010;121:2169-75.
33. Anderson JL, Horne BD. Birthing the genetics of peripartum cardiomyopathy. Circulation 2010;121(20):2157-9.

34. Moioli M, Menada MV, Bentivoglio G, Ferrero S. Peripartum cardiomyopathy. Arch Gynecol Obstet. 2010;281(2):183-8.

35. Cole WC, Mehta JB, Roy TM, Downs CJ. Peripartum cardiomyopathy: echocardiogram to predict prognosis. Tennessee Medicine 2001;94(4):135-8.

36. Carlson KM, Browning JE, Eggleston MK, Gherman RR. Peripartum cardiomyopathy presenting as lower extremity arterial thromboembolism. A case report. J Reprod Med Obstet Gynecol. 2000;45(4):351-3.

37. Bennani SL, Loubaris M, Lahlou I, Haddour N, Badidi M, Bouhouch R, et al. Postpartum cardiomyopathy revealed by acute lower limb ischemia. Ann Cardiol Angeiol (Paris). 2003;52(6):382-5.

38. Box LC, Hanak V, Arciniegas JG. Dual coronary emboli in peripartum cardiomyopathy. Tex Heart Inst J. 2004;31(4):442-4.

39. Lasinska-Kowara M, Dudziak M, Suchorzewska J. Two cases of postpartum cardiomyopathy initially misdiagnosed for pulmonary embolism. Can J Anaesth. 2001;48(8):773-7.

40. Diao M, Diop IB, Kane A, Camara S, Sarr M, Ba SA, Diouf SM.Electrocardiographic recording of long duration (Holter) of 24 hours during idiopathic cardiomyopathy of the peripartum. Arch Mal Coeur Vaiss. 2004;97(1):25-30.

41. Bertrand E, Langlois J, Renambot J, Chauvet L, Ekra A. La myocardiopathie du post-partum : à propos de 25 cas. Arch Mal Coeur Vaiss. 1977;70(2):169-78.

42. Fadouach S, Matar N, Meziane M, Tahiri A, Chraibi N. Syndrome de Meadows: cardiomyopathie du pèripartum. Rev Fr Gynecol Obstet 1994;89(6);3356.

43. Lampert MB, Lang RM. Peripartum cardiomyopathy. Am Heart J. 1995;130(4):860-70.

44. Blauwet LA, Cooper LT. Diagnosis and management of peripartum cardiomyopathy. Heart. 2011;97(23):1970-81.

45. Forster O, Hilfiker-Kleiner D, Ansari AA, Sundstrom JB, Libhaber E, Tshani W, et al. Reversal of IFN-gamma, oxLDL and prolactin serum levels correlate with clinical improvement in patients with peripartum cardiomyopathy. Eur J Heart Fail. 2008;10(9):861-8.

46. Demakis JG, Rahimtoola SH, Sutton GC, Meadows WR, Szanto PB, Tobin JR, et al. Natural course of peripartum cardiomyopathy. Circulation. 1971;44(5):1053-61.

47. Saltzberg MT, Szymkiewicz S, Bianco NR. Characteristics and outcomes of peripartum versus nonperipartum cardiomyopathy in women using a wearable cardiac defibrillator. J Card Fail. 2012;18(1):121-7.

48. Sliwa K, Blauwet L, Tibazarwa K, Libhaber E, Smedema JP, Becker A, et al. Evaluation of 
bromocriptine in the treatment of acute severe peripartum cardiomyopathy: a proof-of-concept pilot study. Circulation. 2010;121(13):1465-73.

49. Bozkurt B, Villaneuva FS, Holubkov R, Tokarczyk T, Alvarez RJ Jr, MacGowan GA, et al. Intravenous immune globulin in the therapy of peripartum cardiomyopathy. J Am Coll Cardiol. 1999;34(1):17780 .

50. Murali S, Baldisseri MR. Peripartum cardiomyopathy. Crit Care Med. 2005;33(10)Suppl:340-6.

51. Amos A, Jaber WA, Russell SD. Improved outcomes in peripartum cardiomyopathy with contemporary. Am Heart J. 2006;152(3):509-13.
52. Goland S, Modi K, Bitar F. Clinical profile and predictors of complications in peripartum cardiomyopathy. J Card Fail. 2009;15:645-50.

53. Elkayam U, Akhter, MW, Singh H, Khan S, Bitar F, Hameed A, et al. Pregnancy-associated cardiomyopathy: clinical characteristics and a comparison between early and late presentation. Circulation. 2005;111(16):2050-5.

54. Pyatt RJ, Dubey G. Peripartum cardiomyopathy: current understanding, comprehensive management review and new developments. Postgrad Med J. 2011;87(1023):34-9.

Cite this article as: Sharma P, Kumar B. Peripartum cardiomyopathy: an obstetric review. Int J Reprod Contracept Obstet Gynecol 2017;6:371-8. 